\title{
Structural Characterization of Luteolin Glycosides Flavonoids from Indian Plantation White Sugar
}

\author{
VIKESH KUMAR \\ Department of Chemistry, Awadhesh Pratap Singh University, Rewa, Madhya Pradesh-486003, India. \\ *Corresponding author E-mail: vikeshkumaraps@gmail.com
}

http://dx.doi.org/10.13005/ojc/360425

(Received: July 15, 2020; Accepted: August 16, 2020)

\begin{abstract}
Luteolin flavonoid is useful in a variety of dietary constituents and can be used as medicine to protect and suppress the growth of different human cancers. These flavonoids may increase the level of reactive oxygen species, and have value as chemopreventive substances. In this study, a medium grade (L-30) sugar was obtained from a reputed north Indian sugar manufacturer which had turned slightly yellowish due to a long storage period for flavonoids identification. Flavonoids are more stable than other sugar colorants and persist into sugar crystals. A resin-based column chromatography method has been developed for the extraction of three luteolin glycosides flavonoids from Indian plantation white sugar. The fractionation of the colorants was done according to their size by gel permeation chromatography, and finally their isolation and purification by thin-layer chromatography. The detected flavonoids were: luteolin-6-C- $\beta$-glucopyranoside, luteolin-7-O- $\beta$ glucopyranoside and luteolin-7-O- $\beta$-galactopyranoside. Ultraviolet and Nuclear magnetic resonance spectroscopy techniques were used for the structural characterization of flavonoids.
\end{abstract}

Keywords: Flavonoid, Plantation White Sugar, Extraction, Resin.

\section{INTRODUCTION}

The quality of sugar is directly related to its color value. The color incorporated in sugar crystals may originate from the cane plant itself or may be formed during processing. The former comprises colorants such as chlorophyll, carotenes, xanthophylls, anthocyanins, and flavonoids ${ }^{1-2}$. Flavonoids such as tricin, isoorientin, isovitexin, and apigenin glycosides have been identified in sugarcane leaves, liquor, and molasses ${ }^{3-8}$. However, flavonoids have promising applications in food and pharmaceuticals ${ }^{9-10}$.
The luteolin group of flavonoids, sugar are joined to the A ring by carbon-carbon bonds at 6 or 8 positions that occur as $\mathrm{C}$-glycosides. Sugar house products may contain luteolin as it does in the case of other mill syrup and molasses. These phenomena developed from other studies dealing with luteolin6-C-glucoside, iso-orientin-0-rhamnosylglucoside, luteolin-6-C-glucosyl-7-0-glucoside, iso-orientintri-0-glucoside and luteolin-6-8-di-C-glycosides in sugarcane leaf ${ }^{11}$, and iso-orientin-7-0-methyl ether, iso-orientin7,3'-0-dimethyl ether, 6-methoxyluteolin, orientin-7,3'-0-dimethyl ether and other luteolin derivatives in mill syrup ${ }^{12-13}$. Luteolin, a dietary

This is an Open Access article licensed under a Creative Commons license: Attribution 4.0 International (CC- BY). Published by Oriental Scientific Publishing Company @ 2018

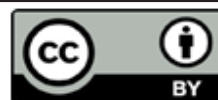


flavonoid is possessed to have anti-thyroid, antiviral, anticancer, and antioxidant ${ }^{14-15}$, characteristics found in fruits, herbs ${ }^{16}$, sugarcane mill syrup, and bagasse ${ }^{17-18}$. Thus, analysis of flavonoids in sugar and other sugar products commodities like bagasse, mill syrup, and molasses have become essential requirements for the sugar industry.

These flavonoids find their way into the sugar crystal through sugarcane, sugar production process, and enzymatic reaction. No systematic study has been carried out to date to isolate and identify the natural colorants persisting into the granulated direct consumption white sugar made in our country. It is imperative to determine the flavonoids components in sugar samples in India. This paper aims to provide the structural characterization of sugar flavonoids that make it such a useful recipient in the pharmaceutical and sugar industry. The study also includes the application of gel permeation chromatography for the fractionation of sugar flavonoids. Spectral analysis like UV and NMR were used for flavonoids characterization.

\section{EXPERIMENTAL}

\section{Chemicals}

All solvents like methanol, hydrochloric acid, and ammonia (HPLC grade) were purchased from Merck (Mumbai, India).

\section{Sample Collection}

A medium grade (L-30) sugar was obtained in 2019 from a reputed North Indian sugar manufacturer.

\section{Preparation of Solution}

Plantation white sugar $(25 \mathrm{~g})$ was diluted with $100 \mathrm{~mL}$ distilled water to prepare a $25{ }^{\circ} \mathrm{Bx}$ (degree Brix) solution. The solution was filtered and the $\mathrm{pH}$ was adjusted to about 4 with concentrated $\mathrm{HCl}^{19}$.

\section{Extraction and Cleanup}

A XAD-4 macroporous adsorption resin (60 mesh particle size, pore diameter $40 \mathrm{~A}^{0}$, surface area $=725 \mathrm{~m}^{2} / \mathrm{g}$ ) was used for recovering sugar flavonoids. The resin was filled in a chromatographic column preconditioned with hydrochloric acid and sodium hydroxide ${ }^{20}$. The sugar extract was collected into a $100 \mathrm{~mL}$ beaker. Dry colorants $(20 \mathrm{~g})$ were dissolved with $100 \mathrm{~mL}$ distilled water and 1-2 drops of concentrated $\mathrm{HCl}$ was added to precipitate polymeric colorant $^{19}$. For flavonoids recovery, a mixture of methanol: ammonia: water (40:4:56) was used. The solution was filtered with Millipore $0.22 \mu \mathrm{m}$ sterile filter, the solution was then adsorbed onto dextran gel- Sephadex (particle size $=50-150 \mu$, water regain $=5 \mathrm{~mL} / \mathrm{g}$, gel bed volume $=10 \mathrm{~mL} / \mathrm{g}$ ) at a rate of 0.33 $\mathrm{mL} / \mathrm{min}$ and elution was done with water at the same rate. Three fractions were collected separately for each technique which was then chromatographed on cellulose TLC plate ${ }^{20}$. The fractions were evaporated and investigated for identification.

\section{Analysis}

The final extracts were analyzed in DMSO- $d_{6}$ containing TMS as the internal standard reference (JEOL AL $500 \mathrm{MHz}$ ) ${ }^{1} \mathrm{H}$ and ${ }^{13} \mathrm{C}$ NMR spectrometer. Shimadzu UV-1601 spectrophotometer was used for UV-Vis analysis in the range of $200-800 \mathrm{~nm}^{20}$.

\section{RESULTS AND DISCUSSION}

Flavonoids, the yellow-colored molecules are more stable than other colorants and pass over to the final stages of processing. According to Smith and Paton ${ }^{1}$, the group of flavonoids is the most critical to sugar color being responsible for up to $30 \%$ (at $\mathrm{pH} 7)$ of the raw sugar color. The structural studies of plantation white sugar afford three flavonoids (1-3), they are luteolin-6-C- $\beta$-glucopyranoside (1), luteolin-7-O-ß-glucopyranoside (2), and luteolin7-O- $\beta$-galactopyranoside (3). The Rf values, color reaction and spectral analysis (UV and NMR) of 3 analyzed flavonoids ${ }^{21-23}$ are shown in Table 1-3. These spectral results confirm that the purification method was successfully employed to isolate pure fractions of different flavonoids and were in good agreement with those previously published ${ }^{21}$. Flavonoids 1, 2, and 3 were characterized for the first time from the sugar under investigation (Figure 1-9). 
Kumar., Orient. J. Chem., Vol. 36(4), 773-779 (2020)

Table 1: Preliminary identification of flavonoids

\begin{tabular}{cccc}
\hline Compound & Rf value & UV light & UV/NH \\
\hline luteolin-6-C- $\beta$-glucopyranoside & 0.43 (TBA) & Deep purple & Yellow-green \\
luteolin-7-O- $\beta$-glucopyranoside & 0.16 (TBA) & Deep purple & Light yellow \\
luteolin-7-O- $\beta$-galactopyranoside & 0.30 (TBA) & Deep purple & Yellow \\
\hline
\end{tabular}

Table 2: The UV-Vis Spectral Data with Different Diagnostic Shift Reagents of Flavonoids in Plantation White Sugar

\begin{tabular}{|c|c|c|c|c|c|c|}
\hline Compound & Methanol & $\begin{array}{l}\text { Sodium } \\
\text { Methoxide }\end{array}$ & $\begin{array}{l}\text { Aluminum } \\
\text { Chloride }\end{array}$ & $\begin{array}{l}\text { Aluminum Chloride/ } \\
\text { Hydrochloric Acid }\end{array}$ & $\begin{array}{l}\text { Sodium } \\
\text { Acetate }\end{array}$ & $\begin{array}{c}\text { Sodium Acetate/ } \\
\text { Boric Acid }\end{array}$ \\
\hline \multirow[t]{4}{*}{ luteolin-6-C- $\beta$-glucopyranoside } & 256 & 265 & 276 & 266 sh & 275 & 264 \\
\hline & 270sh & 275 sh & 302sh & 278 & 321 & 370 \\
\hline & 350 & 405 & 330 & 365 & 390 & 425sh \\
\hline & & & 423 & 382 & & \\
\hline \multirow[t]{4}{*}{ luteolin-7-O- $\beta$-glucopyranoside } & 254 & 262 & 273 & 275 & 260 & 260 \\
\hline & 264sh & 298sh & 300sh & 290 & $265 \mathrm{sh}$ & 374 \\
\hline & 345 & 392 & 326 & 355 & 403 & \\
\hline & & & 430 & 387 & & \\
\hline \multirow[t]{4}{*}{ luteolin-7-O- $\beta$-galactopyranoside } & 254 & 265 & 272 & 274 & 260 & 258 \\
\hline & 262sh & 300sh & 300sh & 290 & 263sh & 372 \\
\hline & 350 & 392 & 325 & 350 & 403 & \\
\hline & & & & 385 & & \\
\hline
\end{tabular}

Table 3: ${ }^{13} \mathrm{C}$ NMR data of luteolin-6-C- $\beta$ glucopyranoside, luteolin-7-O- $\beta$-glucopyranoside, and luteolin-7-0- $\beta$-galactopyranoside

\begin{tabular}{cccc}
\hline Position & Compound 1 & Compound 2 & Compound 3 \\
\hline 1 & - & - & - \\
2 & 164.4 & 164.5 & 166.9 \\
3 & 102.8 & 103.1 & 104.1 \\
4 & 182.5 & 181.9 & 184.0 \\
5 & 160.8 & 161.1 & 162.9 \\
6 & 105.0 & 99.5 & 101.1 \\
7 & 164.6 & 163.0 & 164.8 \\
8 & 98.6 & 94.7 & 96.0 \\
9 & 156.5 & 157.0 & 159.0 \\
10 & 104.4 & 105.3 & 107.1 \\
$1^{\prime}$ & 122.4 & 121.3 & 123.4 \\
$2^{\prime}$ & 114.4 & 113.6 & 114.2 \\
$3^{\prime}$ & 146.3 & 145.8 & 147.1 \\
$4^{\prime}$ & 150.1 & 150.0 & 151.9 \\
$5^{\prime}$ & 116.1 & 116.0 & 119.2 \\
$6^{\prime}$ & 119.8 & 119.2 & 116.8 \\
$1 \mathrm{~g}$ & 73.8 & 99.9 & 101.7 \\
$2 \mathrm{~g}$ & 71.2 & 73.1 & 74.7 \\
$3 \mathrm{~g}$ & 79.2 & 76.4 & 71.3 \\
$4 \mathrm{~g}$ & 71.2 & 69.6 & 77.9 \\
$5 \mathrm{~g}$ & 82.4 & 77.2 & 78.4 \\
$6 \mathrm{~g}$ & 62.1 & 60.6 & 62.4 \\
\hline & & & \\
\hline
\end{tabular}

Compound 1 UV-Vis maxima 256, 270 (shoulder), $350 \mathrm{~nm}$ and was ascribed to luteolin6 -C- $\beta$-glucopyranoside. The ${ }^{1} \mathrm{H}$ NMR spectra of compound 1 indicated the presence of luteolin-6-C$\beta$-glucopyranoside, chemical shift of $\mathrm{H}-3$, and $\mathrm{H}-8$ at $\delta_{\mathrm{H}} 6.61(1 \mathrm{H})$ and $6.23(1 \mathrm{H}, \mathrm{d}, \mathrm{J}=2.3)$. Two aromatic doublet at $\delta_{\mathrm{H}} 6.82$ and 7.42 (each $1 \mathrm{H}, \mathrm{d}, \mathrm{J}=2.3$ ) for $\mathrm{C}-2$ ' and $\mathrm{C}-5$ ' proton and one olefinic proton at $\delta_{H} 7.49$ for C-6' proton and a methoxyl group at $\delta_{\mathrm{H}} 3.88$ that showed correlation with $\delta 146.33$ (C-3'), 150.14 (C-4'), 160.88 (C-5), and 164.62 (C-7) bearing hydroxyl group respectively (Table 3 ). Spectral analysis of the known flavonoid allowed us to establish luteolin-6-C- $\beta$-glucopyranoside as the structure of compound $1^{21-23}$.<smiles>O=c1cc(-c2ccc(O)c(Cl)c2)oc2cc(O)c(C3OCC(O)C(O)C(O)C3O)c(O)c12</smiles>

Chemical structure of luteolin-6-C- $\beta$-glucopyranoside

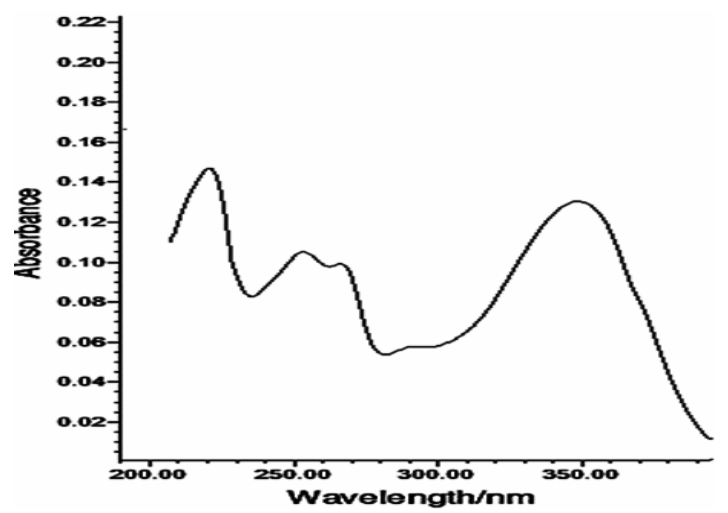

Fig. 1. UV-spectra of luteolin-6-C- $\beta$-glucopyranoside 


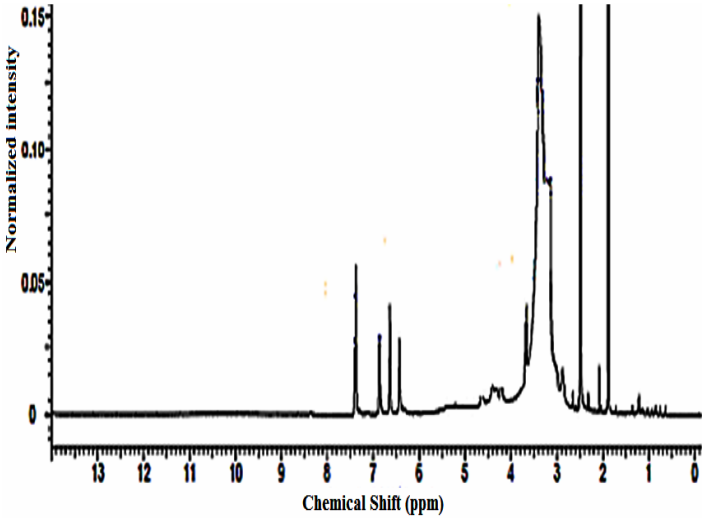

Fig. 2. ${ }^{1} \mathrm{H}$ NMR spectrum of luteolin-6-C- $\beta$-glucopyranoside

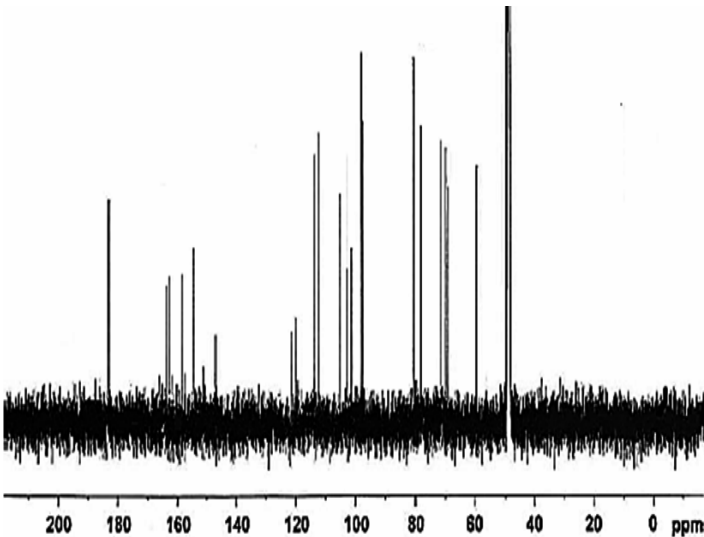

Fig. $3 .{ }^{13} \mathrm{C}$ NMR spectrum of luteolin-6-C- $\beta$-glucopyranoside

Compound 2 showed UV-Vis maxima at 254, 264 (shoulder), $345 \mathrm{~nm}$. This compound was tentatively assigned as luteolin-7-O- $\beta$ glucopyranoside. The results of the test for flavonoids identification of sugar are shown in Table 2. The ${ }^{1} \mathrm{H}$ NMR spectrum of compound 2 shows an anomeric proton at $\delta_{\mathrm{H}} 5.08(1 \mathrm{H}, \mathrm{d}, \mathrm{J}=7.65)$, whereas compound 3 showed one aromatic proton at $\delta_{\mathrm{H}} 5.5(1 \mathrm{H}, \mathrm{d}, \mathrm{J}=7.65)$. The compounds 2 and 3 showed $\mathrm{H}-3$ and $\mathrm{H}-6$ at $\delta_{\mathrm{H}} 6.61$ and 6.43 . ${ }^{1} \mathrm{H}$ NMR spectrum of compounds shows doublet at $6.9(1 \mathrm{H}, \mathrm{d}, \mathrm{J}=2.3 \mathrm{~Hz})$.<smiles>O=c1cc(-c2ccc(O)c(O)c2)oc2cc(OC3OC4CC(O)[C@H](O)[C@@H](O)C3O4)cc(O)c12</smiles>

Chemical structure of luteolin-7-0- $\beta$-glucopyranoside

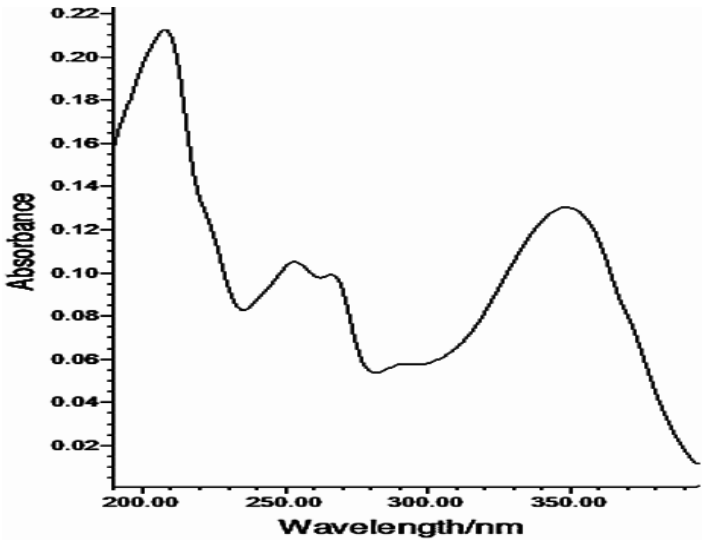

Fig. 4. UV-spectra of luteolin-7-0- $\beta$-glucopyranoside

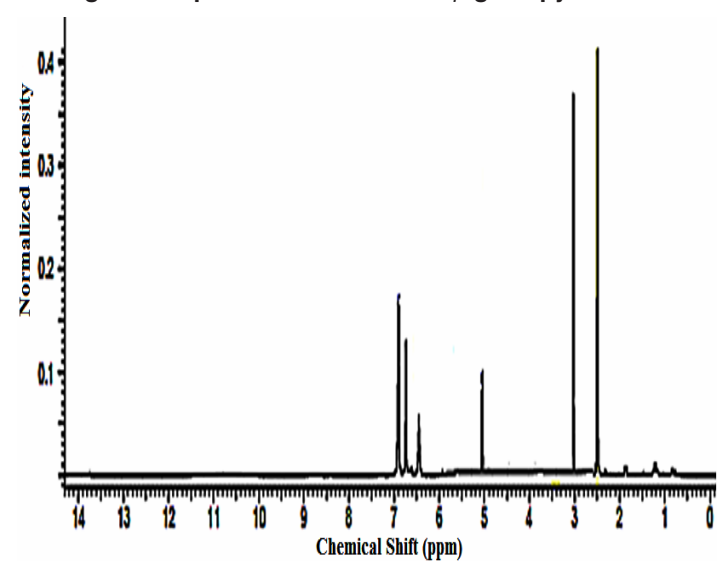

Fig. 5. ${ }^{1} \mathrm{H}$ NMR spectra of luteolin-7-0- $\beta$-glucopyranoside

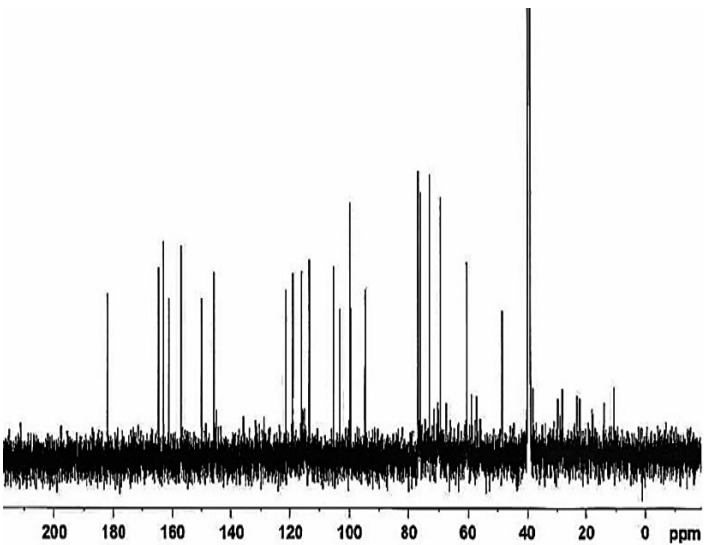

Fig. $6 .{ }^{13} \mathrm{C}$ NMR spectra of luteolin-7-O- $\beta$-glucopyranoside

Compound 3 exhibited two peaks at 254 and $350 \mathrm{~nm}$ that were matched with the luteolin-7O- $\beta$-galactopyranoside spectrum ${ }^{21}$.

The ${ }^{13} \mathrm{C}$ NMR signals of compound 2 and compound 3 exhibited the presence of a ketone carbonyl at $\delta c 181.9$ for luteolin-7-O- $\beta$ - 
glucopyranoside, and 184.0 for luteolin-7-O$\beta$-galactopyranoside. Compound 2 showed two olefinic carbons at $\delta c 164.5$ and 103.1, whereas compound 3 exhibited signals of two olefinic carbons at $\delta c 166.9$ and 104.1. The ${ }^{13} \mathrm{C}$ NMR signals showed the presence of hydroxyl carbon position of compound 2 at 161.1 and 150.0 whereas compound 3 exhibited signals at 162.9 and 151.9 respectively.<smiles>O=c1cc(-c2ccc(O)cc2)oc2cc(OC3OC4CC(O)[C@H](O)[C@@H](O)[C@H]3O4)cc(O)c12</smiles>

Chemical structure of luteolin-7-0- $\beta$-galactopyranoside

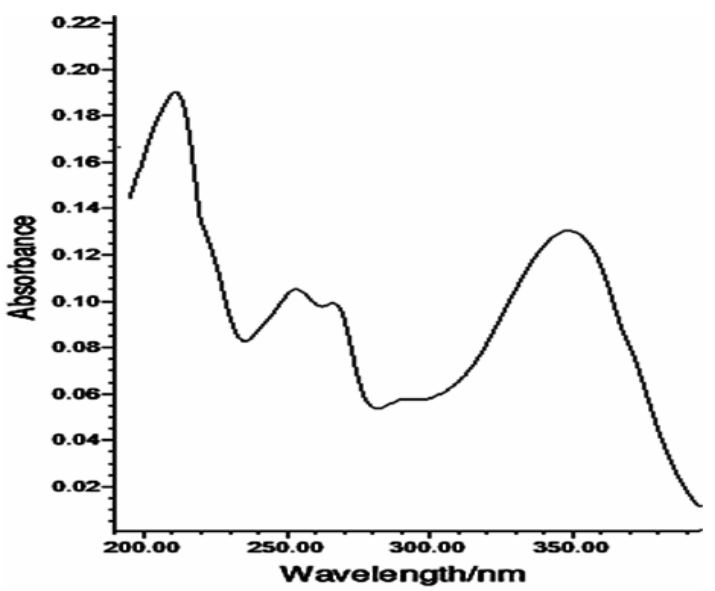

Fig. 7. UV spectra of luteolin-7-O- $\beta$-galactopyranoside

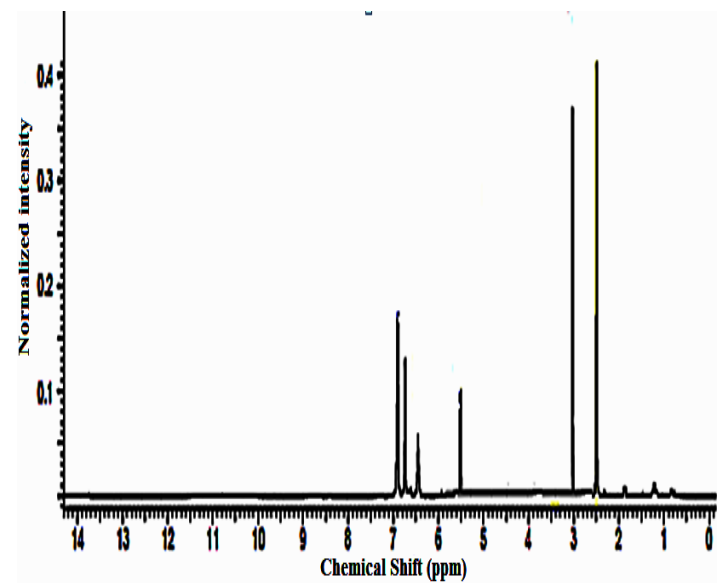

Fig. 8. ${ }^{1} \mathrm{H}$ NMR spectra of luteolin-7-O- $\beta$-galactopyranoside

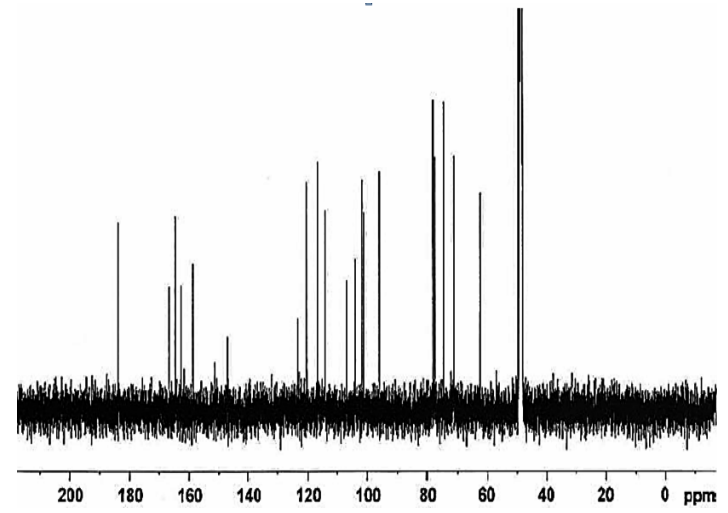

Fig. 9. ${ }^{13} \mathrm{C}$ NMR spectra of luteolin-7-0- $\beta$-galactopyranoside

The data suggest that compound 2 had six sugar attachment sites at $(\delta 99.9,77.2,76.4,73.1$, 69.6 , and 60.6) revealed the presence of luteolin-7O- $\beta$-glucopyranoside. The ${ }^{13} \mathrm{C}$ NMR chemical shifts of the sugar carbons $(\delta 101.7,78.4,77.9,74.7$, 71.3, and 62.4) showed the presence of luteolin-7O- $\beta$-galactopyranoside (Table 3). The data allowed us to establish luteolin-7-O- $\beta$-glucopyranoside and luteolin-7-O- $\beta$-galactopyranoside as the structure of the compound by comprising of the spectral data with literature value ${ }^{21-23}$.

The presence of flavonoids in sugarcane has become a global phenomenon. Authors have reported the presence of flavones, anthocyanins, and flavonols, along with chalcones and chlorogenic acids in sugarcane and cane juice from India $20,24-25$, and abroad ${ }^{26-27}$. Flavonoids mainly flavones enters and accumulates into the sugar crystal through the sugar processing of flavonoids containing commodities (sugarcane, cane juice, molasses, and sugar house products) and may affect sugar quality 20,28 .

\section{CONCLUSION}

The resin-based gel chromatography method developed for the identification of flavonoids was found to be simple, accurate, and sensitive. Three active flavonoids components from Indian Plantation white sugars were isolated (luteolin-6-C$\beta$-glucopyranoside, luteolin-7-O-ß-glucopyranoside, and luteolin-7-O- $\beta$-galactopyranoside). It is concluded that sugarcane and sugar house products extract could potentially be used for food additives and the development of useful natural compounds. 


\section{ACKNOWLEDGMENT}

The author wishes to acknowledge the support of Prof. V. K. Agrawal, Awadhesh Pratap
Singh University, Rewa for this work.

\section{Conflict of interest}

The author declares no conflict of interest.

\section{REFERENCES}

1. Smith, P.; Paton, N. H. Sugarcane flavonoids. Sugar. Technol. Rev., 1985, 12, 117-42.

2. Yao, L. H., Jiang Y. M.; Shi J, Tomás-Barberán F. A.; Datta, N.; Singanusong, R.; Chen, S.S. Flavonoids in food and their health benefits. Plant. Foods. Hum. Nutr., 2004, 59(3), 113-22.

3. Mc Ghie, T.K. Analysis of sugar cane flavonoids by capillary zone electrophoresis. J Chromatogr., 1993, 634, 107-12.

4. Vila, F.C.; Colombo, R.; de Lira, T.O.; Yariwake, J.H. HPLC microfractionation of flavones and antioxidant (radical scavenging) activity of Saccharum officinarum L. J. Braz. Chem. Soc., 2008, 19, 903-908.

5. De Armas, R.; Martinez, M.; Vincente, C.; Legaz, M.E. Free and conjugated polyamines and phenols in raw and alkaline-clarified sugarcane juice. J. Agric. Food. Chem., 1999, 47, 3086-3092.

6. Colombo, R.; Yariwake, J.H.; Queroz, E.F.; Ndjoko, K.; Hostettmann, K. On-line identification of minor flavones from sugarcane juice by LC/UV/MS and post-column derivatization. J. Braz. Chem. Soc., 2009, 20, 1574-1579.

7. Takara, K.; Ushijima, K.; Wada, K.; Iwasaki, H.; Yamashita, M. Phenolic compounds from sugarcane molasses possessing antibacterial activity against carcinogenic bacteria. J. Oleo. Sci., 2007, 56, 611-614.

8. Balasundram, N.; Sundram, K.; Samman, $\mathrm{S}$. Phenolic compounds in plants and agriindustrial by-products: Antioxidant activity, occurrence, and potential uses. Food. Chem., 2006, 99,191-203.

9. Zheng, R., Su, S., Li, J., Zhao, Z., Wei, J., Fu, X., Liu, R.H. Recovery of phenolics from the ethanolic extract of sugarcane (Saccharum officinarum $L$.) baggase and evaluation of the antioxidant and antiproliferative activities. Ind. Crops. Prod., 2017, 107, 360-369.

10. Zhao, Y., Zhu, L.C., Yu, S.J., Zhao, Z.G. HPLCUV-ESI-MS methods for flavonoid profiling of sugarcane juice extract. Sugar. Ind., 2013, 138, 525-531.

11. Farber, L.; Carpenter, F.G. Plant pigments as colorants in cane sugars', 1972 Tech. Sess. Cane. Sugar. Refining. Res., 1975, 23-31.

12 Misra, K. Mishra, C.S. Flavonoids of Saccharum officinarum flowers. Ind. J. Chem., 1979, 18B, 88.

13. Mishra, C.S.; and Misra, K. 5-7Dimethylapigenin 4'-0-D-glucopyranoside from Saccharum officinarum leaves. Curr. Sci., 1978, 47(5) 152.

14. Devi, K.P.; Rajavel, T.; Nabavi, S.F.; Seltzer, W.N.; Ahmadi, A. ; Mansouri, K.; Nabavi, S.M. Hesperidin: A promising anticancer agent from nature. Ind. Crops. Prod., 2015, 76, 582-589.

15. Lin, Y.; Shi, R.; Wang, X.; Shen, H. Luteolin, a flavonoid with potentials for cancer prevention and therapy. Curr. Canc. Drug. Targ., 2008, 8 (7) 634-646.

16. Martin, K.R. Targeting apoptosis with dietary bioactive agents. Exp. Biol. Med., 2006, 231 (2) 117-129.

17. Kadam, U.S.; Ghosh, S.B.; Suprasannat, P.; Devasagayam, T.P.A.; Bapat, V.P. Antioxidant activity in sugarcane juice and its protective role against radiation-induced DNA damage. Food. Chem., 2008, 106(3) 1154-1160.

18. Zheng, R.; Su, S.; Zhou, H.; Yan, H.; Ye, J.; Zhao, Z.; You, L.; Fu, X. Antioxidant / antihyperglycemic activity of phenolics from sugarcane (Saccharum officinarum L.) bagasse and identification by UHPLC-HR-TOFMS. Ind. Crops. Prod., 2017, 101, 104-111.

19. Yinrong, L.; Yeap, F. Polyphenolic constituents of blackcurrant seed residue. Food. Chem., 2003, 80, 71-76.

20. Kumar, V. Isolation and identification of anticancer apigenin glycosides flavonoids from plantation white sugar. Orient. J. Chem., 2020, 36(3) 544-549. 
21. Mabry, T.J.; Markham, K.R.; Thomas, M.B. The Systematic Identification of Flavonoids. (Springer-Verlag, New York., 1970).

22. Lu, Y.; Foo, L. Y. Polyphenolics of Salvia--a Review. Phytochem., 2002, 59(2) 117-140.

23. Kawashty, S. A.; El-Garf, I.A. The Flavonoid Chemosystematics of Egyptian Verbena Species. Biochem. Syst. Ecol., 2000, 28(9) 919-921.

24. Kumar,V.; Kumari, O.; Singh, S.; Upadhyay, R.; Tripathi, M. R. Validation of analytical method for determination of quercetin concentration in cane sugar and cane juice. Anal. Chem. An Ind. J., 2012, 11(6) 227-230.

25. Kumar,V.; Kumari, O.; Singh, S.; Upadhyay, R.; Tripathi, M. R. Isolation \& identification of flavonoid 'rutin' from Indian plantation white sugars. Int. J. Appl. Chem., 2012, 8(1), 57-62.
26. Payet, B.; Shum, A.; Smadja J. Assessment of antioxidant activity of cane brown sugars by ABTS and DPPH radical scavenging assays: Determination of their polyphenolic and volatile constituents. J. Agri. Food. Chem., 2005, 53, 10074-10079.

27. Payet B, Shum Cheong Sing A, Smadja J. Comparison of the concentrations of phenolic constituents in cane sugar manufacturing products with their antioxidant activities. $J$. Agric. Food. Chem., 2006, 54, 7270-7276.

28. Godshell, M.A.; Roberts, E.J.; New Orleans: SPRI; 1982. Phenolics in sugar products: Their role in flavour and color production. Proceedings of the Sugar Processing Research Conference., 1982, 47-72 